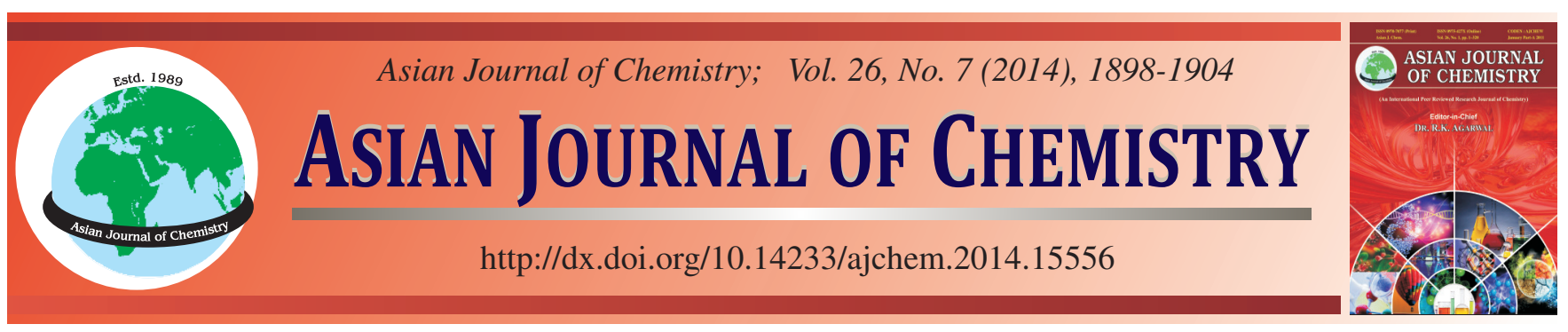

\title{
Swelling Kinetics and Rheological Characterization of Methyl Acrylate-Vinyl Acetate-Acrylic Acid Hydrogels
}

Muhammad Aslam Malana ${ }^{1, *}$, Gulistan Firdous ${ }^{1}$, Abeera Javed ${ }^{1}$, Zafar Iqbal Zafar ${ }^{1}$ and Muhammad Saleem Khan ${ }^{2}$

${ }^{1}$ Institute of Chemical Sciences, Bahauddin Zakariya University, Multan-60800, Pakistan

${ }^{2}$ Centre of Excellence in Physical Chemistry, University of Peshawar, Peshawar, Pakistan

*Corresponding author: Fax: +92 61 9210085; Tel: +92 61 9210092; E-mail: draslammalana@gmail.com

\begin{abstract}
In the present studies, swelling kinetics of crosslinked methyl acrylate-vinyl acetate-acrylic acid (MA-VA-AA) hydrogels and rheological studies of uncrosslinked MA-VA-AA hydrogels have been undertaken. The swelling response of hydrogels to $\mathrm{pH}$, temperature and concentration of methyl acrylate has been investigated. It was observed that equilibrium swelling $\left(\mathrm{w}_{\mathrm{e}}\right)$ increased with $\mathrm{pH}$ and temperature whereas, it decreased with methyl acrylate contents. The value of $0.5<\mathrm{n}<1$ obtained in the present studies at all the temperatures, $\mathrm{pH}$ and methyl acrylate concentrations indicated non-fickian mechanism of the diffusion process. In order to evaluate kinetic order of swelling, Fick's model and Schott's model were applied to the experimental data. Better value of correlation coefficient $\left(R^{2}>0.96\right)$ obtained in case of Fick's model showed that swelling behavior of the hydrogels followed first order kinetics. The values of fluidity index (n) obtained from the flow curves at all the temperatures were less than 1.0 indicating non-newtonian behavior of all the hydrogels. The magnitude of Bingham yield stress increased with methyl acrylate concentration and decreased with temperature. Consistency coefficient (K), however, increased with methyl acrylate concentration. This could be interpreted in terms of higher degree of entanglement in the gel containing greater contents of methyl acrylate. Maximum swelling of MA-VA-AA hydrogel at $\mathrm{pH} 8$ suggests that it may be used as drug delivery device for delivering drug at colonic part of intestine $(\mathrm{pH} 7-8)$.
\end{abstract}

Keywords: Rheology, Shear thinning, Swelling, Methyl acrylate-vinyl acetate-acrylic acid hydrogel.

\section{INTRODUCTION}

Hydrogels are cross-linked hydrophilic polymers capable of absorbing large volume of water but are insoluble in it due to their network structures ${ }^{1-3}$. Ability of hydrogels to retain water depends mainly upon elasticity of their network, degree of crosslinking, and porosity of the polymer and nature of the functional groups ${ }^{4}$ present in it.

Increasing attention, however, has been focused in the past several years in hydrogels which display controllable changes in volume in response to small environmental changes such as $\mathrm{pH}$, temperature, ionic strength, $e t c^{5-8}$. Due to significant difference in physiological $\mathrm{pH}$ at different body sites in normal as well as pathological conditions, $\mathrm{pH}$ responsive and thermo responsive hydrogels have been extensively studied ${ }^{9-12}$. All these efforts have led the researchers to better understanding and control the stimuli responsiveness of hydrogels and also to predict their equilibrium swelling by changing their conditions. Prediction of equilibrium swelling ratio is important in designing and utilizing these materials for specific applications $^{13,14}$.
Due to compatibility in physiological characteristics of the designed (material) hydrogel and large intestine, drug delivery to intestine can be achieved. This can be done by using colonic microflora mainly anaerobic or facultative anaerobic micro-organisms involved in production of many enzymes as a vehicle of transfer ${ }^{15}$.

Because of having slightly higher $\mathrm{pH}$ than its proximal small intestine, another way which is more convenient for drug delivery at colon is through oral dosage. This can be achieved by using $\mathrm{pH}$ sensitive polymeric hydrogels which swell to minimum in the acidic $\mathrm{pH}$ ( $\mathrm{pH}$ of stomach), giving almost complete protection to the encapsulated drug and undergo maximum swelling in the slightly alkaline $\mathrm{pH}$ to release most of the drug ${ }^{16}$.

In the present work, methyl acrylate-vinyl acetate-acrylic acid (MA-VA-AA) terpolymeric hydrogels containing varying amounts of methyl acrylate are synthesized which swell maximum at $\mathrm{pH} 8.0$ (colonic $\mathrm{pH}$ ) and show no swelling at acidic $\mathrm{pH}$. Effect of $\mathrm{pH}$, methyl acrylate contents on swelling has been investigated. Furthermore, rheological characteristics of these gels have also been studied at four different temperatures. 
This manuscript deals with swelling as well as rheological characterization of MA-VA-AA tercopolymeric gel with particular emphasis on the effect of methyl acrylate concentration on these characteristics.

\section{EXPERIMENTAL}

The chemicals used in the present studies are methyl acrylate (99\%, Merck) vinyl acetate (99\%, Fluka), acrylic acid (99\%, Fluka) ethyleneglycoldimethacrylate (100\%, Fluka), benzoyl peroxide (100\%, Merck) and deionized water.

In order to study the swelling as well as rheological behaviour of MA-VA-AA polymer, two types of polymers i.e. cross-linked polymer and polymer without crosslinking have been synthesized. The crosslinked polymers were used for the study of swelling behaviour and the polymers without crosslinking were used for rheological studies.

Monomers: Vinyl acetate (VA), acrylic acid (AA) were used in equal volume ratio, whereas the concentration of methyl acrylate (MA) was used in different grades $(0.5,0.75,1.0$ and $1.25 \mathrm{~mL}$ for the gels $\mathrm{G} 1, \mathrm{G} 2, \mathrm{G} 3$ and G4 respectively) keeping the volume of ethylene-glycoldimethacrylate (crosslinking agent) constant. Benzoyl per oxide (BPO) was added $1 \% \mathrm{w} / \mathrm{v}$ as an initiator in each preparation. The monomers, crosslinking agent and initiator were taken in screw caped tubes. Ethanol as a solvent $(100 \% \mathrm{v} / \mathrm{v})$ was added to the reaction mixture. The contents of the tubes were mixed thoroughly and nitrogen gas was bubbled through the reaction mixture so that the interference of oxygen may be prevented. Test tubes were placed in thermostat (water bath) and radical polymerization was carried out through slow heating scheme to ensure the uniform formation of polymeric column ${ }^{17}$.

Increment of temperature was designed in such a way that $5{ }^{\circ} \mathrm{C}$ was raised after every hour starting from $38-68{ }^{\circ} \mathrm{C}$. At $68{ }^{\circ} \mathrm{C}$ the polymeric column began to build up. This temperature was maintained for $3 \mathrm{~h}$ to ensure completion of the polymerization reaction. The smooth polymeric cylinders were removed from the tubes and left over night for setting at room temperature. Hydrogels obtained in long cylindrical shapes were cut into pieces of 3-4 mm thickness. Thoroughly washed and dried discs (xerogels) were preserved for later evaluation.

The samples of polymers for rheological studies were synthesized by following the same procedure as mentioned above for the crosslinked polymers. However, varying concentrations of the monomers were used as required.

Kinetic measurements of swelling: Swelling of polymer as a function of $\mathrm{pH}$ was carried out at different temperatures $\left(35,40\right.$ and $\left.45^{\circ} \mathrm{C}\right)$. Swelling of the hydrogels with different methyl acrylate amounts $(0.5,0.75,1.0$ and $1.25 \mathrm{~mL})$ was monitored gravimetrically. Buffer solutions of different $\mathrm{pH}$ ranging from 1-8 were prepared. Prior to use, the discs of hydrogels were kept in an oven at $80{ }^{\circ} \mathrm{C}$ for $2 \mathrm{~h}$ to remove moisture contents. The xerogels thus obtained were weighed and their initial thickness and diameter were measured with the help of screw gauge. These xerogels were put in buffer solutions and were weighed after specific intervals of time. The hydrogel discs were taken out from the buffer solutions and weighed after removing excess water from the surface of the discs. The process was continued until the equilibrium swelling was obtained.
Rheometric measurements: Rheometric measurements of polymeric hydrogels MA-VA-AA (uncrosslinked) were carried out in the temperature range of $10-40^{\circ} \mathrm{C}$ by MCR 302 rheometer of Anton paar, Germany. In a typical measurement a pressure of 5 bars was attained by switching on the compressor. Rheometer was switched on for self-calibration. After getting the status "Ok" the software (Rheoplus) was initiated and control panel was opened. After acquiring the required temperature, the measuring device (cone and plate pp 25 with diameter $1 \mathrm{~mm}$ ) was attached to the instrument. Zero gaps were adjusted through the control panel. The sample was placed on the plate and brought to the position of measurement. The experimental measurements were made in the above mentioned temperature range. The parameters such as viscosity and shear stress of the polymer were recorded as a function of shear rate.

\section{RESULTS AND DISCUSSION}

Terpolymeric gels with varying concentration of methyl acrylate were synthesized to get better control on swelling characteristics. During synthesis, different changes in appearance were observed. Initially, all the samples were homogenous and transparent. With gradual change in temperature, samples having different amounts of methyl acrylate showed different behaviour. For example, the samples having higher concentration of methyl acrylate showed no considerable change in appearance whereas, those with lower concentration exhibited little milkiness at the bottom. The milkiness shifted up towards the sides of the tubes at lower temperature. This early milkiness may be interpreted in terms of temporary hydrogen bond formation ${ }^{17}$. Further increase in temperature, resulted in milkiness in all the samples. It was observed that whole of the sample having lower concentration of methyl acrylate turned more milky and those with comparatively higher concentration of methyl acrylate, remained less milky. This observation reflects hydrophobic nature of methyl acrylate.

Thermogravimetric analysis: The synthesized polymeric samples were thermally characterized by using Universal V4.2 E TA instrument. A representative thermogram of hydrogel (MA-VA-AA) having $1 \mathrm{~mL}$ methyl acrylate is illustrated in Fig. 1. It indicates a total weight loss of $98 \%$ in the temperature range of 25 to $800{ }^{\circ} \mathrm{C}$. A weight loss of $16.26 \%$ at $127.05^{\circ} \mathrm{C}$ can be related to the loss of free water. The curve shows a weight loss of $20.65 \%$ at $243.09{ }^{\circ} \mathrm{C}$ which may be ascribed to the loss of hydrated water and alcoholic contents. The $3 \mathrm{rd}$ drop in weight at $412.61{ }^{\circ} \mathrm{C}$ is observed with the total weight loss of $70.43 \%$ which may be attributed to the degradation of organic contents present in the sample. Similar pattern of thermal decomposition of other samples (M1 and M3) was observed.

FTIR analysis: The hydrogels were characterized by Fourier transform infrared spectroscopy (FTIR). The peak observed at $956 \mathrm{~cm}^{-1}$ can be related to $=\mathrm{C}-\mathrm{H}$ bending vibrations. The peak at $1207 \mathrm{~cm}^{-1}$ is attributed to the presence of $\mathrm{C}-\mathrm{O}$ stretching vibrations. The peaks at $1749-1697 \mathrm{~cm}^{-1}$ can be ascribed to $\mathrm{C}=\mathrm{O}$ stretching vibrations. The peak observed for the polymer at $2910 \mathrm{~cm}^{-1}$ owing to $\mathrm{C}-\mathrm{H}$ stretching vibrations. The peaks in the region $3813-3579 \mathrm{~cm}^{-1}$ show O-H stretching vibrations due to the presence of water. 


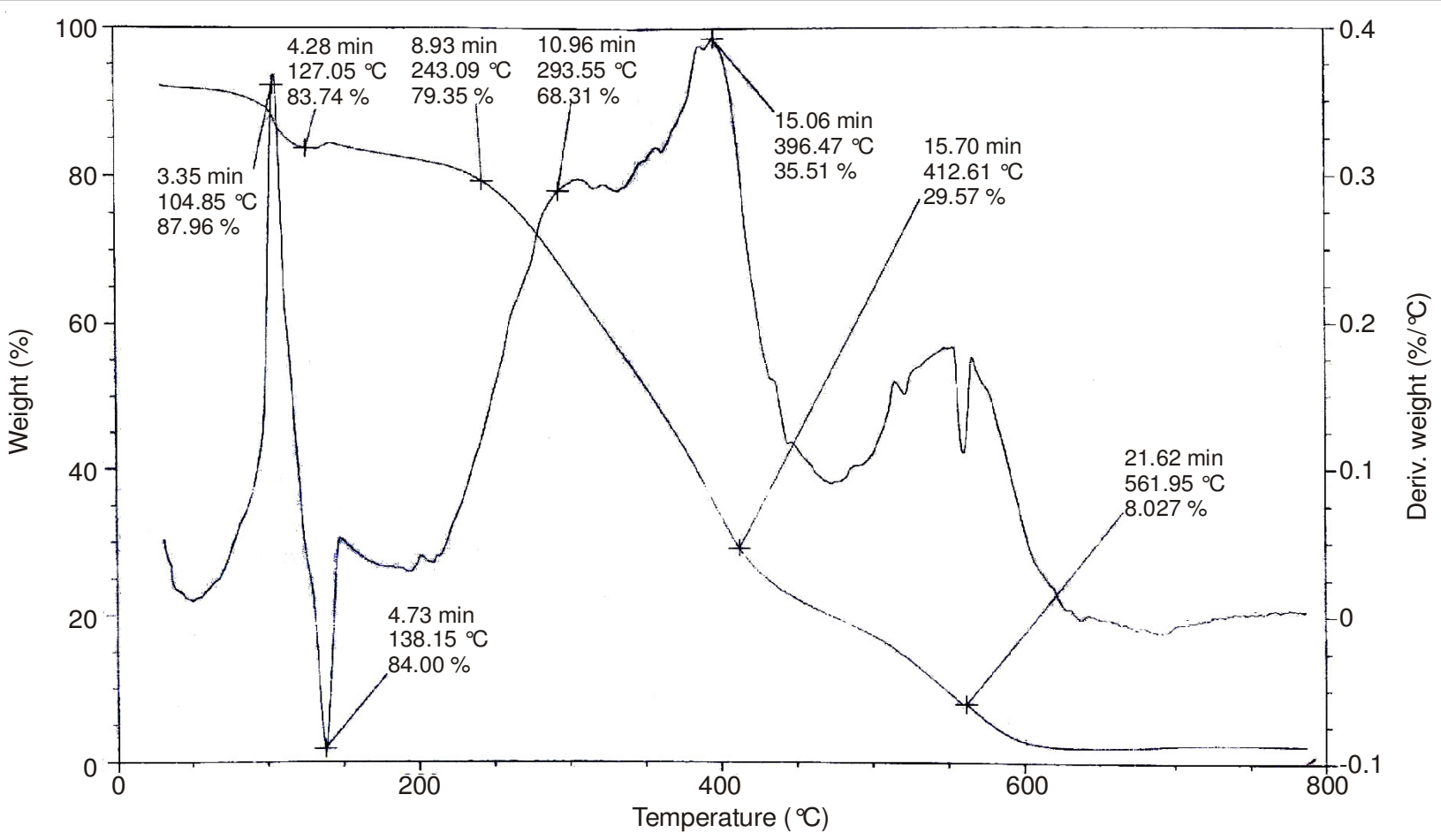

Fig. 1. TGA/DTG curve of MA-VA-AA Hydrogel

SEM analysis: SEM micrographs were recorded to examine the changes in surface morphology before and after swelling of MA-VA-AA hydrogel (Fig. 2). It is noticed that the surface of the hydrogel before swelling (Fig. 2a) is rough and there are large number of small pores in the structure of the gel. This indicates the swelling ability of the hydrogel. After swelling, (Fig. 2b) surface of the gel becomes smooth due to the retention of water inside porous structure of the gel. A wide range of pore size $(8.0 \mu \mathrm{m}$ to $52 \mu \mathrm{m})$ is indicated in SEM micrographs of VA-MA-AA hydrogels before swelling. This may be due to the presence of different moieties inside the gel structure as a result of a variety of monomers used in the hydrogels.

Swelling behavior of hydrogels: Swelling behavior of the hydrogel was investigated at five different $\mathrm{pH}$ values (i.e. $1.0,4.0,5.5,7.4$ and 8.0) and at three different temperatures (i.e. 35,40 and $45^{\circ} \mathrm{C}$ ). Results of present investigations showed that the gels with greater contents of methyl acrylate were initially transparent but turned milky with uptake of the penetrant. This milkiness can be interpreted in terms of hydrogen bond formation between hydrophilic parts of the gels and water molecules. During swelling, in general, more increase in diameter than in thickness of the gel was observed. This can be attributed to same rate of swelling throughout the polymer network (i.e. margin as well as bulk). Less milkiness in the hydrogels containing higher contents of methyl acrylate demonstrates hydrophobic behavior of these monomers.

The swelling behaviour of these hydrogels, however, was completely characterized by determining the equilibrium swelling $\left(\mathrm{w}_{\mathrm{e}}\right)$, the diffusion exponent $(\mathrm{n})$ and kinetic order of swelling.

Equilibrium swelling $\left(\mathbf{w}_{\mathrm{e}}\right)$ : The equilibrium swelling $\left(\mathrm{w}_{\mathrm{e}}\right)$ which is a measure of the ability of a gel to retain maximum quantity of water is calculated from the expression (eqn. 1) 18, $19^{19}$.
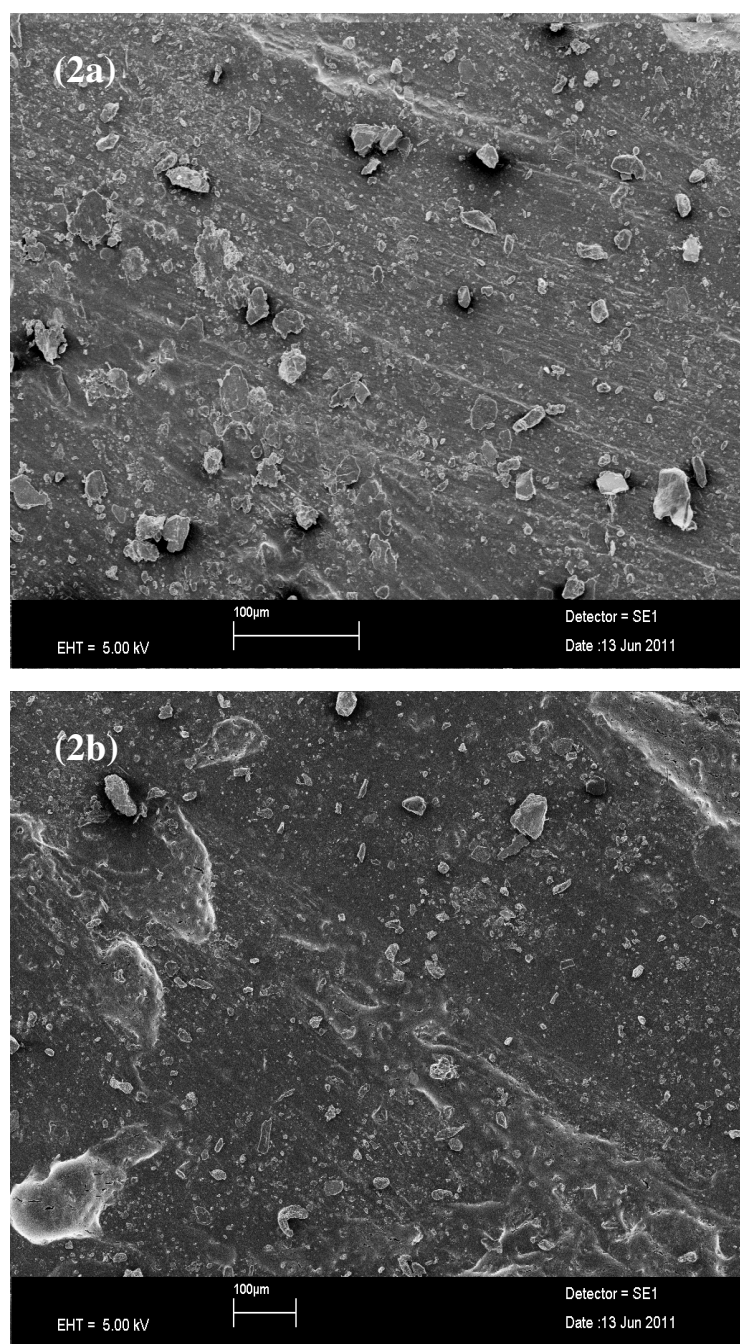

Fig. 2. SEM image of MA-VA-AA hydrogel (A1 at $\mathrm{pH}=8$ ) (a) before swelling (b) after swelling 


\begin{tabular}{|c|c|c|c|c|c|c|c|c|c|}
\hline \multicolumn{10}{|c|}{$\begin{array}{l}\text { TABLE-1 } \\
\text { PARAMETERS OBTAINED FROM FICK'S AND SCOTT'S MODELS FOR MA-VA-AA } \\
\text { HYDROGELS AT DIFFERENT pH AND TEMPERATURES }\end{array}$} \\
\hline \multicolumn{5}{|c|}{ Effect of $\mathrm{pH}$} & \multicolumn{5}{|c|}{ Effect of temperature } \\
\hline \multirow{2}{*}{ Sample } & \multicolumn{2}{|c|}{ Fick's Model } & \multicolumn{2}{|c|}{ Schott's Model } & \multirow{2}{*}{ Sample } & \multicolumn{2}{|c|}{ Fick's Model } & \multicolumn{2}{|c|}{ Schott's Model } \\
\hline & $\mathrm{n}$ & $\mathrm{R}^{2}$ & $\mathrm{R}^{2}$ & $\mathrm{w}_{\mathrm{e}}$ & & $\mathrm{n}$ & $\mathrm{R}^{2}$ & $\mathrm{R}^{2}$ & $\mathrm{w}_{\mathrm{e}}$ \\
\hline \multicolumn{5}{|c|}{$\mathrm{pH}=5.5$} & \multicolumn{5}{|c|}{$\mathrm{T}=35^{\circ} \mathrm{C}$} \\
\hline G2 & 0.95 & 0.96 & 0.60 & 0.821 & F1 & 0.69 & 0.98 & 0.83 & 0.79 \\
\hline G3 & 0.87 & 0.96 & 0.83 & 0.543 & $\mathrm{~F} 2$ & 0.55 & 0.97 & 0.82 & 0.772 \\
\hline G4 & 0.92 & 0.96 & 0.73 & 0.352 & F3 & 0.57 & 0.98 & 0.92 & 1.78 \\
\hline G5 & 0.90 & 0.99 & 0.77 & 0.35 & $\mathrm{~F} 4$ & 0.44 & 0.96 & 0.88 & 0.56 \\
\hline \multicolumn{5}{|c|}{$\mathrm{pH}=7.4$} & \multicolumn{5}{|c|}{$\mathrm{T}=40^{\circ} \mathrm{C}$} \\
\hline G2 & 0.65 & 0.98 & 0.95 & 0.888 & F1 & 0.58 & 0.98 & 0.86 & 1 \\
\hline G3 & 0.81 & 0.96 & 0.95 & 0.727 & F2 & 0.53 & 0.98 & 0.90 & 0.772 \\
\hline G4 & 0.88 & 0.99 & 0.86 & 0.529 & F3 & 0.64 & 0.96 & 0.92 & 2.88 \\
\hline G5 & 0.68 & 0.99 & 0.96 & 0.442 & F4 & 0.57 & 0.98 & 0.82 & 2.27 \\
\hline \multicolumn{5}{|c|}{$\mathrm{pH}=8.0$} & \multicolumn{5}{|c|}{$\mathrm{T}=45^{\circ} \mathrm{C}$} \\
\hline G2 & 0.74 & 0.99 & 0.98 & 0.794 & F1 & 0.69 & 0.98 & 0.92 & 1.18 \\
\hline G3 & 0.71 & 0.97 & 0.96 & 0.772 & $\mathrm{~F} 2$ & 0.46 & 0.97 & 0.95 & 0.926 \\
\hline G4 & 0.96 & 0.99 & 0.60 & 0.789 & F3 & 0.55 & 0.96 & 0.95 & 2.44 \\
\hline G5 & 0.63 & 0.99 & 0.96 & 0.569 & F4 & 0.51 & 0.97 & 0.96 & 1.32 \\
\hline
\end{tabular}

$$
\frac{\mathrm{t}}{\mathrm{w}_{\mathrm{t}}}=\frac{1}{\mathrm{k}_{\mathrm{s}} \mathrm{w}_{\mathrm{e}}^{2}}+\frac{\mathrm{t}}{\mathrm{w}_{\mathrm{e}}}
$$

where, $\mathrm{w}_{\mathrm{t}}, \mathrm{w}_{\mathrm{e}}$ and $\mathrm{k}_{\mathrm{s}}$ are weight of the gel at time $\mathrm{t}$, equilibrium swelling and swelling rate constant, respectively. Plots of $t / \mathrm{w}_{\mathrm{t}}$ against time $t$ for all the hydrogels (G2, G3, G4 and G5) at all the $\mathrm{pH}$ and temperature were linear $\left(\mathrm{R}^{2}>0.90\right)$. The value of $\mathrm{W}_{\mathrm{e}}$ calculated as inverse of the slope for all the gels at different $\mathrm{pH}$ and temperatures are given in Table- 1 .

Effect of pH: It is evident from the Table-1 that the value of $\mathrm{w}_{\mathrm{e}}$ for each gel increases with increase in $\mathrm{pH}$ of the medium. This may be due to the fact that as $\mathrm{pH}$ of the medium exceeds $\mathrm{pKa}$ (4.50) of the carboxylic acid (acrylic acid) present in the gel, acidic protons are removed. Carboxylate ions thus produced enhance affinity of the gel towards the penetrant. As $\mathrm{pH}$ becomes higher more anions are produced as a result of ionization and greater is the affinity of the gel for the penetrant. It is further noticed that increase in the value of $w_{e}$ with $\mathrm{pH}$ is observed except for the gel G4 at $\mathrm{pH} 8$ containing balanced amount of monomers (Fig. 3).

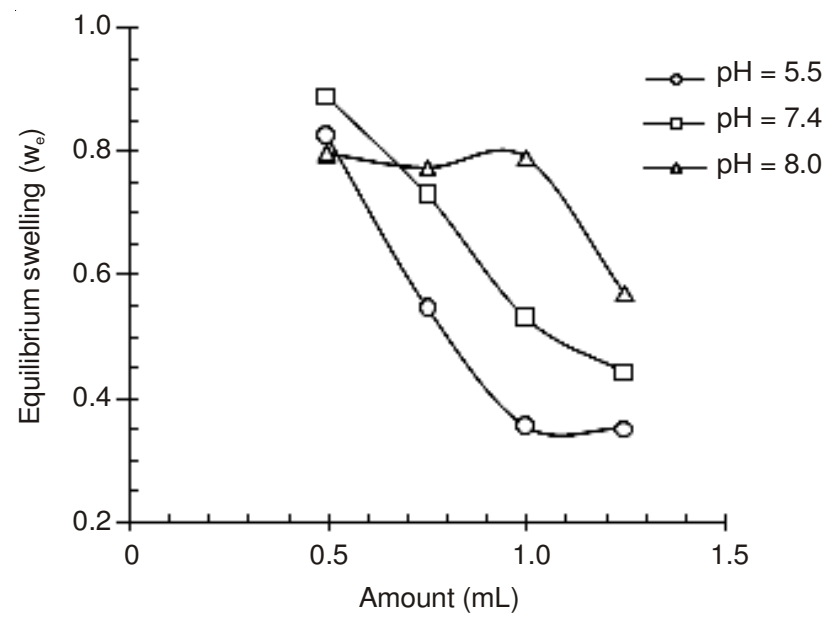

Fig. 3. Plot showing variation of equilibrium swelling $\left(\mathrm{w}_{\mathrm{e}}\right)$ with methyl acrylate contents in MA-VA-AA hydrogel at different $\mathrm{pH}$
Effect of temperature: Swelling experiments for all the gels (G2, G3, G4 and G5) were carried out at three different temperatures $\left(35,40\right.$ and $\left.45^{\circ} \mathrm{C}\right)$. The values of $\mathrm{w}_{\mathrm{e}}$ (Table-1) increases with increase in temperature. This can be explained in a way that when temperature increases, intramolecular hydrogen bonds within the polymer network are broken. This makes the gel structure less compact and hence the swelling is increased in case of all the gels.

Effect of methyl acrylate concentration: In the present investigations gels with varying amounts of methyl acrylate (keeping other two monomers constant) were synthesized to study the effect of methyl acrylate concentration in the gel on swelling behavior of MA-VA-AA hydrogel systems. The values of equilibrium swelling $\left(\mathrm{w}_{\mathrm{e}}\right)$ calculated for each system are listed in Table-1. The results show that by increasing methyl acrylate content in the gel the value of $\mathrm{w}_{\mathrm{e}}$ decreased at all the $\mathrm{pH}$ and temperature. This can be attributed to the hydrophobic nature of methyl acrylate. However, anomalous behavior in case of the gel G4 at $\mathrm{pH} 8$ which shows maximum swelling among all the gels can be explained in terms of the balanced amounts of the monomers in the gel system.

Diffusion exponent (n): Diffusion exponent (n) calculated from (eqn. 2) gives useful information about mechanism of diffusion during swelling of hydroge ${ }^{20}$. If $\mathrm{n}<0.5$ it follows fickian mechanism whereas, $0.5<\mathrm{n}<1.0$ indicates non-fickian or anomalous type of diffusion ${ }^{21-23}$. The value of $n=1.0$ represents chain relaxation (superb diffusion) mechanism.

$$
\frac{\mathrm{W}_{\mathrm{t}}}{\mathrm{w}_{\mathrm{e}}}=\mathrm{Kt}^{\mathrm{n}}
$$

where, $\mathrm{K}$ is proportionality constant and $\mathrm{n}$ is diffusion exponent.

In the present studies the value of $\mathrm{n}$ obtained for all the gels are less than 1 at all $\mathrm{pH}$ and temperature range studied. This shows that swelling of these gels exhibit non-fickian behavior of diffusion process. 
Kinetic order of swelling: Kinetic order of swelling gives reliable information about mechanism of swelling. In the present studies Fick's and Schott's models were employed to evaluate the kinetic order of swelling of MA-VA-AA hydrogels $^{21}$. In all the cases it was observed that Fick's model gives a better fit $\left(\mathrm{R}^{2}>0.96\right)$ to the experimental data as compared to Schott's model $\left(\mathrm{R}^{2}>0.60\right)$ (Table-1). This shows that diffusion of the penetrant into these gels follow first order kinetics indicating that swelling of these hydrogels is diffusion controlled.

Rheological studies: Rheological characterization of the materials furnishes reliable information about structure, viscosity and their usefulness in many fields such as drug delivery systems and tissue engineering ${ }^{24}$. Flow properties of the hydrogels play an important role in drug release from the hydrogel to the specific tissue surface ${ }^{25}$. In the present studies rheograms of uncrosslinked MA-VA-AA hydrogels were obtained at four different temperatures $\left(10,20,30\right.$ and $\left.40{ }^{\circ} \mathrm{C}\right)$. It is evident from these plots that viscosity of the hydrogel decreases with shear rate at all the temperatures showing shear thinning behavior of these hydrogels. The zero shear viscosity of all the hydrogels also decreased with temperature. In order to test their validity the rheological data of the present investigations were fitted to different mathematical models such as Ostwald's Model (eqn. 3), Ostwald de-Waele model (eqn. 4), Atapattu model (eqn. 5), Bingham model (eqn. 6), Modified Bingham Model (eqn. 7) and Casson model (eqn. 8) ${ }^{26-31}$.

$$
\begin{aligned}
\eta & =K \gamma^{n-1} \\
\tau & =K \gamma^{n} \\
\tau & =\tau_{0}+\mu \gamma(\text { at shear rate } 0-0.1 \mathrm{~Pa}) \\
\tau & =\tau_{\mathrm{o}}+\mu \gamma \\
\tau & =\tau_{\mathrm{o}}+\mu \gamma+\mathrm{c} \gamma^{2} \\
\tau^{0.5} & =\tau_{\mathrm{o}}^{0.5}+\mu^{0.5} \gamma^{0.5}
\end{aligned}
$$

Ostwald de-waele model fitted well to the experimental data $\left(R^{2}>0.94\right)$ and the values of parameters $n$ (fluidity index) and $\mathrm{K}$ (consistency coefficient) obtained from this model are listed in Table-2. It is evident from the table that values of $n$ in all the cases are less than 1. Departure from unity of these values confirms pseudo-plastic nature of the MA-VA-AA hydrogels. The values of consistency coefficient $(\mathrm{K})$ vary with methyl acrylate contents in the gel and also with temperature. An increase in value of $\mathrm{K}$ with methyl acrylate contents in the gel may be interpreted in terms of higher degree of entanglement at higher concentration of methyl acrylate in the gel. The decrease in the value of $\mathrm{K}$ observed with increasing temperature may be attributed to breakage of temporary hydrogen bonds thus, reducing the degree of entanglements in the hydrogels ${ }^{31}$.

Yield stress: The minimum stress which must be applied to make the material flow is referred to as yield stress. Higher is the value yield stress of the material, better is its transportability. Flow curves obtained by fitting the experimental data to Atapattu model, Bingham model, Modified Bingham model and Casson model are shown in Figs. 4-7. The values of yield stress calculated as intercept of these plots are given in Table3. Modified Bingham model yielded exceptionally higher values of yield stress (32-975 $\mathrm{Pa}$ ) so is excluded from the present discussion.

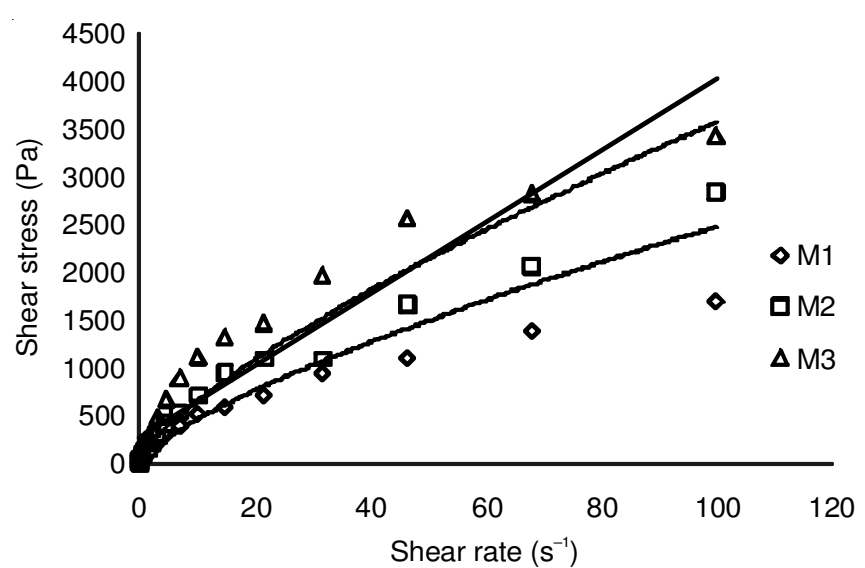

Fig. 4. Steady shear stress of MA-VA-AA polymer as a function of shear rate at $30^{\circ} \mathrm{C}$, Atapattu model

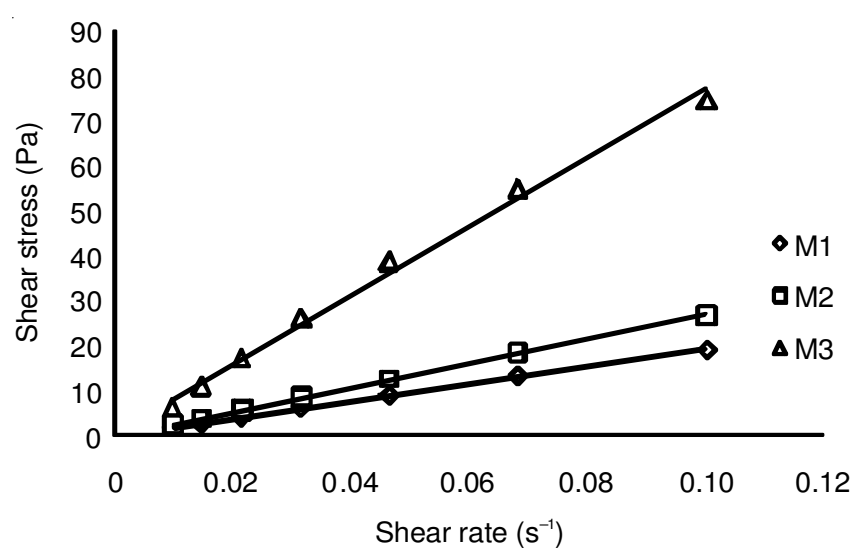

Fig. 5. Steady shear stress of MA-VA-AA polymer as a function of shear rate at $30^{\circ} \mathrm{C}$, Bingham model

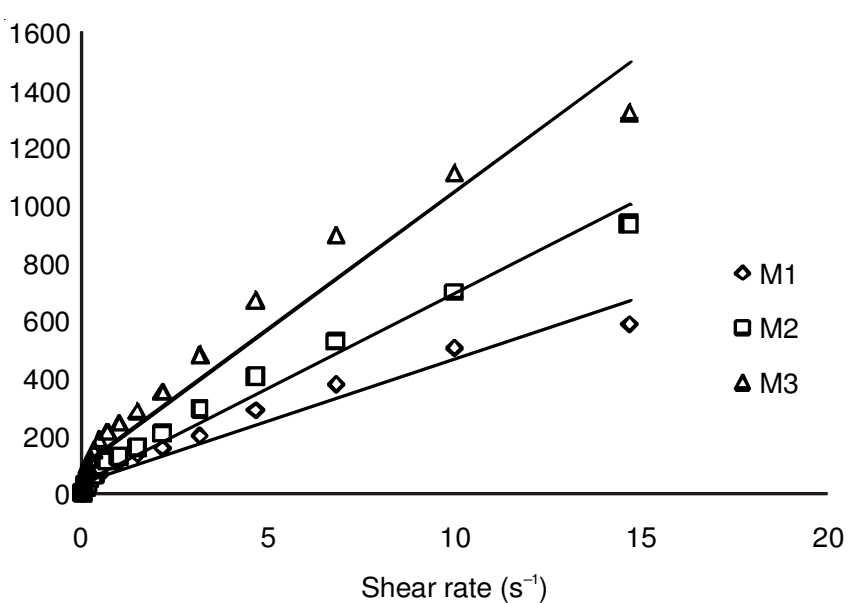

Fig. 6. Steady shear stress of MA-VA-AA polymer as a function of shear rate at $30{ }^{\circ} \mathrm{C}$, modified Bingham model

Atapattu model: Atapattu model was applied to the experimental data in the range of $0-0.1 \mathrm{~s}^{-1}$ shear rate. The values of $\tau_{\mathrm{o}}$ calculated as intercept of shear stress versus shear rate (Fig. 5) is in the range of -0.005 to $2.43 \mathrm{~Pa}$. The negative values of $\tau_{\mathrm{o}}$ obtained in case of hydrogels containing smaller amounts of methyl acrylate have no physical significance. However, the values of $\tau_{\mathrm{o}}$ for other gels increased with increasing methyl acrylate contents, though showing random trend with temperature. 


\begin{tabular}{|c|c|c|c|c|c|c|}
\hline \multicolumn{7}{|c|}{$\begin{array}{c}\text { TABLE-2 } \\
\text { PARAMETERS (n AND K) OBTAINED FROM FLOW CURVES OF MA-VA-AA POLYMER AT DIFFERENT TEMPERATURES }\end{array}$} \\
\hline \multirow{2}{*}{ Sample } & \multicolumn{3}{|c|}{ Ostwald model } & \multicolumn{3}{|c|}{ Ostwald de waele } \\
\hline & $\mathrm{n}$ & $\mathrm{K}$ & $\mathrm{R}^{2}$ & $\mathrm{n}$ & $\mathrm{K}$ & $\mathrm{R}^{2}$ \\
\hline \multicolumn{7}{|c|}{$10{ }^{\circ} \mathrm{C}$} \\
\hline M1 & 0.51 & 233 & 0.92 & 0.51 & 257 & 0.94 \\
\hline M2 & 0.69 & 163 & 0.91 & 0.76 & 141 & 0.98 \\
\hline M3 & 0.60 & 491 & 0.93 & 0.69 & 402 & 0.98 \\
\hline \multicolumn{7}{|c|}{$20^{\circ} \mathrm{C}$} \\
\hline M1 & 0.66 & 114 & 0.97 & 0.80 & 83 & 0.98 \\
\hline M2 & 0.67 & 139 & 0.98 & 0.75 & 118 & 0.98 \\
\hline M3 & 0.59 & 325 & 0.97 & 0.62 & 312 & 0.98 \\
\hline \multicolumn{7}{|c|}{$30^{\circ} \mathrm{C}$} \\
\hline M1 & 0.61 & 108 & 0.98 & 0.73 & 108 & 0.98 \\
\hline M2 & 0.65 & 137 & 0.96 & 0.74 & 137 & 0.98 \\
\hline M3 & 0.59 & 248 & 0.97 & 0.63 & 248 & 0.97 \\
\hline \multicolumn{7}{|c|}{$40^{\circ} \mathrm{C}$} \\
\hline M1 & 0.71 & 85 & 0.98 & & & \\
\hline M2 & 0.60 & 165 & 0.98 & 0.75 & 119 & 0.98 \\
\hline M3 & 0.59 & 210 & 0.93 & 0.60 & 216 & 0.97 \\
\hline
\end{tabular}

TABLE-3

YIELD STRESS VALUES OBTAINED FROM RHEOLOGICAL MODELS FOR MA-VA-AA POLYMER AT DIFFERENT TEMPERATURES

\begin{tabular}{|c|c|c|c|c|c|c|c|c|c|c|}
\hline \multirow{2}{*}{ Sample } & \multicolumn{2}{|c|}{ Atapattu model } & \multicolumn{2}{|c|}{ Modified Bingham model } & \multicolumn{2}{|c|}{ Bingham model (low shear rate) } & \multicolumn{2}{|c|}{ Bingham model (high shear rate) } & \multicolumn{2}{|c|}{ Casson model } \\
\hline & $\mathrm{R}^{2}$ & $\tau_{\mathrm{o}}$ & $\mathrm{R}^{2}$ & $\tau_{\mathrm{o}}$ & $\mathrm{R}^{2}$ & $\tau_{\mathrm{o}}$ & $\mathrm{R}^{2}$ & $\tau_{\mathrm{o}}$ & $\mathrm{R}^{2}$ & $\tau_{\mathrm{o}}$ \\
\hline \multicolumn{11}{|c|}{$10^{\circ} \mathrm{C}$} \\
\hline M1 & 0.99 & -0.005 & 0.97 & 32 & 0.8 & 138 & 0.99 & 849 & 0.93 & 90 \\
\hline M2 & 0.99 & -0.432 & 0.96 & 698 & 0.99 & 32 & 0.98 & 1063 & 0.94 & 29 \\
\hline M3 & 0.99 & 1.680 & 0.89 & 2272 & 0.98 & 131 & 0.91 & 1858 & 0.93 & 106 \\
\hline \multicolumn{11}{|c|}{$20^{\circ} \mathrm{C}$} \\
\hline M1 & 1 & -0.190 & 0.98 & 307 & 0.96 & 32 & 0.96 & 294 & 0.97 & 13 \\
\hline M2 & 0.99 & -0.431 & 0.99 & 533 & 0.97 & 43 & 0.91 & 552 & 0.97 & 21 \\
\hline M3 & .098 & 2.436 & 0.94 & 975 & 0.96 & 121 & 0.94 & 1714 & 0.92 & 94 \\
\hline \multicolumn{11}{|c|}{$30^{\circ} \mathrm{C}$} \\
\hline M1 & 0.99 & -0.267 & 0.99 & 289 & 0.95 & 36 & 0.97 & 468 & 0.94 & 21 \\
\hline M2 & 0.99 & -0.505 & 0.96 & 549 & 0.98 & 39 & 0.98 & 544 & 0.95 & 25 \\
\hline M3 & 0.99 & 0.766 & 0.98 & 517 & 0.95 & 96 & 0.94 & 1094 & 0.94 & 67 \\
\hline \multicolumn{11}{|c|}{$40^{\circ} \mathrm{C}$} \\
\hline M2 & 0.99 & -0.353 & 0.97 & 447 & 0.96 & 47 & 0.98 & 695 & 0.94 & 29 \\
\hline M3 & 0.99 & 1.210 & 0.93 & 975 & 0.98 & 78 & 0.98 & 1140 & 0.92 & 68 \\
\hline
\end{tabular}

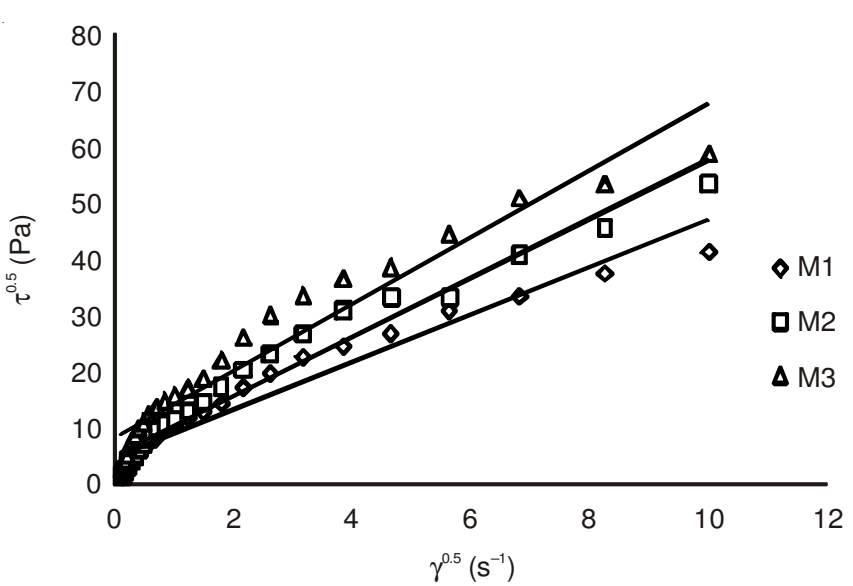

Fig. 7. Steady shear stress of MA-VA-AA polymer as a function of shear rate at $30^{\circ} \mathrm{C}$, Casson model

Bingham model: Fits of the experimental data to Bingham model in two different ranges $(0-15 \mathrm{~Pa})$ and $(15-100 \mathrm{~Pa})$ are separately represented as Fig. 6 . The values of $\tau_{\mathrm{o}}$ obtained from these plots are given in Table- 3 . The magnitude of Bingham yield stress (32-138 Pa) obtained in the present studies increases with methyl acrylate contents at all the temperatures. In case of lower range of shear rate these values of yield stress are in good agreement with those reported in literature for other gels $^{29}$. However, at higher shear rates the magnitude of Bingham yield stress obtained in the present studies is much higher than those reported earlier for other polymeric hydrogels.

Flow curves obtained by fitting the experimental data to Casson model are illustrated in Fig. 7. Yield stress obtained from this model for all the hydrogels is in the range of 13-106 $\mathrm{Pa}$. It has been observed that yield stress increases with methyl acrylate contents showing similar trend as observed in case of Bingham yield stress in these hydrogels. The magnitude of Casson yield stress is smaller than Bingham yield stress in all these hydrogels but the salient point is that Casson yield stress and Bingham yield stress values come in better agreement with each other as concentration of methyl acrylate is increased in MA-VA-AA hydrogels. 


\section{Conclusions}

- Methyl acrylate-vinyl acetate-acrylic acid hydrogel containing minimum amount of methyl acrylate swells maximum showing hydrophobic nature of methyl acrylate.

- Maximum swelling at pH 8 indicates its possible use as drug delivery vehicle for colonic part of intestine.

- Swelling of all these hydrogels in all the media and the temperatures studied follow first order kinetics.

- Shear thinning behavior of the hydrogel as indicated by the flow curves shows its pseudo plastic nature.

\section{REFERENCES}

1. A. Thakur, R.K. Wanchoo and P. Singh, Chem. Biochem. Eng., 25, 181, (2011).

2. J. Guzman, M. Iglesias, E. Riande, V. Compaii and A. Andrio, Polymer, 38, 5227 (1997).

3. M. Sen and O. Güven, Polymer, 39, 1165 (1998).

4. H.V. Chavda and C.N. Patel, Trends Biomater. Artif. Organs, 24, 83 (2010).

5. J.I. Ngadaonye, M.O. Cloonan, L.M. Geever and C.L. Higginbotham, J. Polym. Res., 18, 2307 (2011).

6. B.D. Johnson, D.J. Beebe and W. Crone, Mater. Sci. Eng. C, 24, 575 (2004).

7. E. Ruel-Gariepy and J.C Leroux, Eur. J. Pharm. Biopharm., 58, 409 (2004).

8. Y. Huang, H. Yu and C. Xiao, Carbohydr. Polym., 69, 774 (2007).

9. P. Gupta, K. Vermani and S. Gary, J. Res. Focus., 7, 569 (2002).

10. S. Jin, M. Lui, F. Zhang and A. Niu, Polymer, 47, 1526 (2006).
11. J.M. Rosiak and F. Yoshii, Nucl. Instrum. Methods Phys. Res., 151, 56 (1999).

12. S.L Jahren, M.F. Butler, S. Adams and R.E. Cameron, Macromol. Chem. Phys., 211, 644 (2010).

13. X.H. Xia, J. Yih, N.A. D'Souza and Z.B. Hu, Polymer, 44, 3389 (2003).

14. N.A. Peppas, P. Buresa and W. Leobandung, Eur. J. Pharm. Biopharm., 50, 27 (2000).

15. B. Stubbe, B. Maris and G. Mooter, J. Control. Rel., 75, 103 (2001).

16. S.K. Bajpai and S. Dubey, J. Iran. Polym., 13, 189 (2004).

17. Z.I. Zafar, M.A. Malana and K. Momina, Polymer (Korea), 32, 219 (2008).

18. A.P. Javadi and G.R. Mahdavinia, Turk. J. Chem., 30, 595 (2006).

19. F. Jabbari and S. Nozari, Eur. Polym. J., 36, 2685 (2000).

20. O. Zamoume, S. Thibault, G. Regnié, M.O. Mecherri, M. Fiallo and P. Sharrock, Mater. Sci. Eng. C, 31, 1352 (2011).

21. M.K. Krusic and J. Filipovic, Polymer, 47, 148 (2006).

22. P.L. Ritegar and N.A. Peppas, J. Control. Rel., 5, 23 (1987).

23. J.Z. Yi and L.M Zhang, Eur. Polym. J., 43, 3215 (2007).

24. I.W. Velthoen, J. van Beek, P.J. Dijkstra and J. Feijen, React. Funct. Polym., 71, 245 (2011).

25. E.S. Gil and S.A. Hudson, Prog. Polym. Sci., 29, 1173 (2004).

26. D.D. Atapattu, R.P. Chhabra and P.H.T. Uhlherr, J. Non-Newtonian Fluid Mech., 38, 31 (1990).

27. D. Feys, R. Verhoeven and G. De Schutter, Appl. Rheol., 17, 56244 (2007).

28. A. Yahia and K.H. Khayat, Cement Concret. Res., 31, 731 (2001).

29. R.A.F. Cabral, J.A.W. Gut, V.R.N. Telis and J. Telis-Romero, Braz. J. Chem. Eng., 27, 563 (2010).

30. S. Delgado, R. Villarroel and E. Gonzalez, J. Membr. Sci., 311, 173 (2008).

31. M.T. Islam, N. Rodríguez-Hornedo, S. Ciotti and C. Ackermann, J. Pharm. Res., 21, 1192 (2004). 